\title{
Un nuevo informe presenta casi 100 conelusiones sobre los efectos para la salud de la marihuana y los productos derivados del cannabis
}

The National Academy of Sciences, Engineering and Medicine Informe de Prensa, 12 de enero de 2017

http://www8.nationalacademies.org/onpinews/newsitem.aspx?RecordID=24625\&_ga=1.232139931.524626704.1484279064 Traducido por Salud y Fármacos

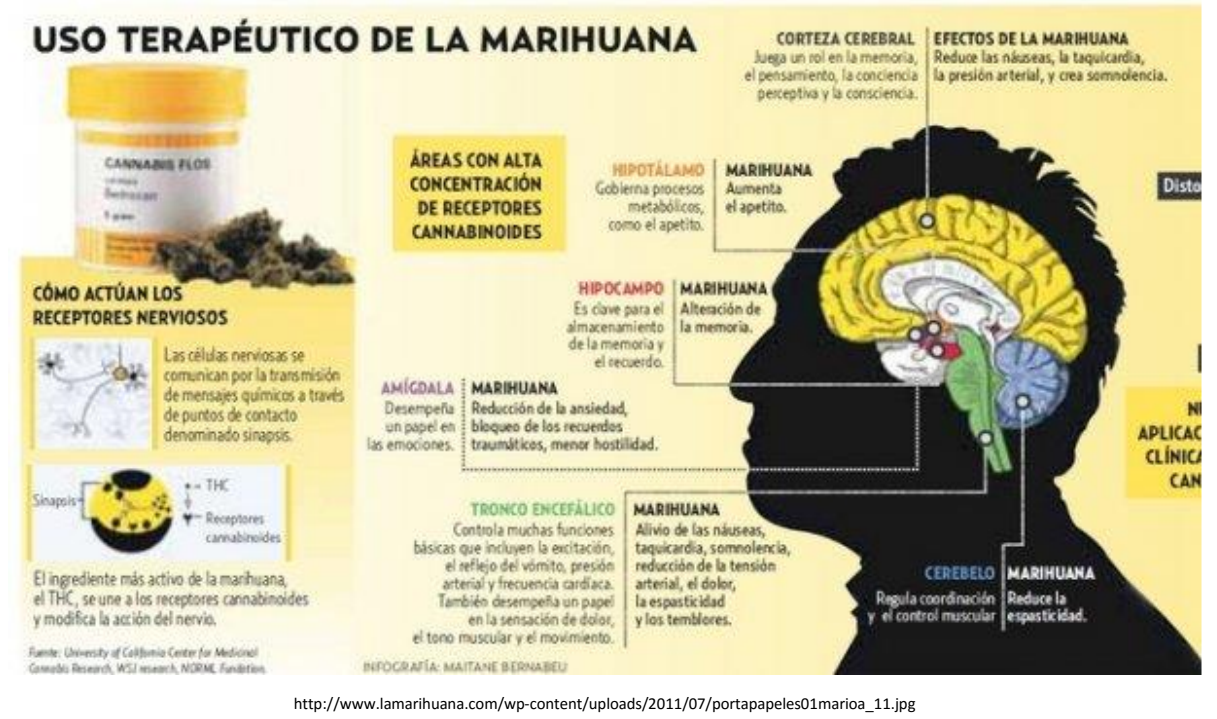

Afirma el resumen que la marihuana ha entrado con fuerza en el mundo de la Medicina; sin embargo, aún su uso con mucho es más recreativo que medicinal ( $90 \%$ a $10 \%)$. Este comité se encargó de hacer una exhaustiva revisión y nos presentan sus conclusiones.

\section{Cifras importantes}

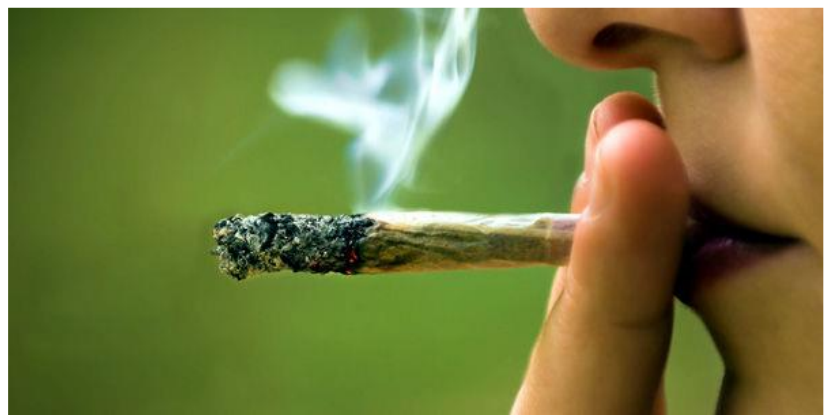

http://WWW.eltiempo.com/contenido///mundo/e--uu-y-canada/IMAGEN/IMAGEN-16394011-2.png

Calculan que cerca de 22 millones de estadounidenses la han usado con fines recreativos en los últimos 30 días. Alertan por el incremento en el número de consumidores recreativos del 6,2 \% (2002) al 8,3\% (2015). 


\section{Efectos terapéuticos}

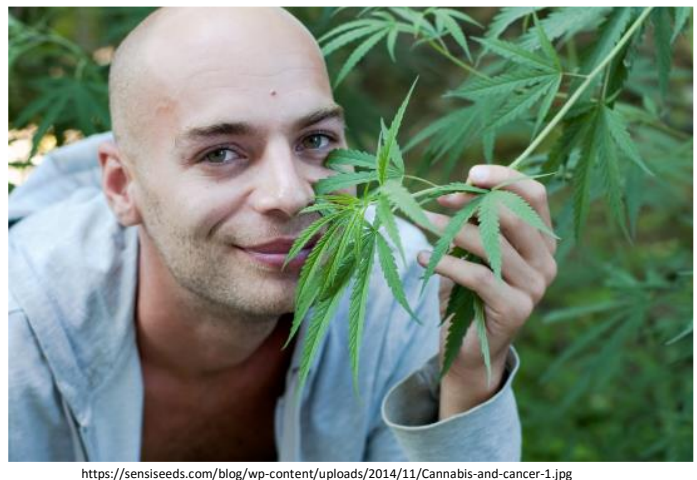

Se ha usado de forma empírica en casos de dolor crónico reduciéndolo de forma significativa. En los espasmos musculares de la esclerosis múltiple ha demostrado, por vía oral, buenos resultados. Igual ha sucedido para el manejo de las náuseas y vómitos inducidos por la quimioterapia.

\section{¡Cuidado!}

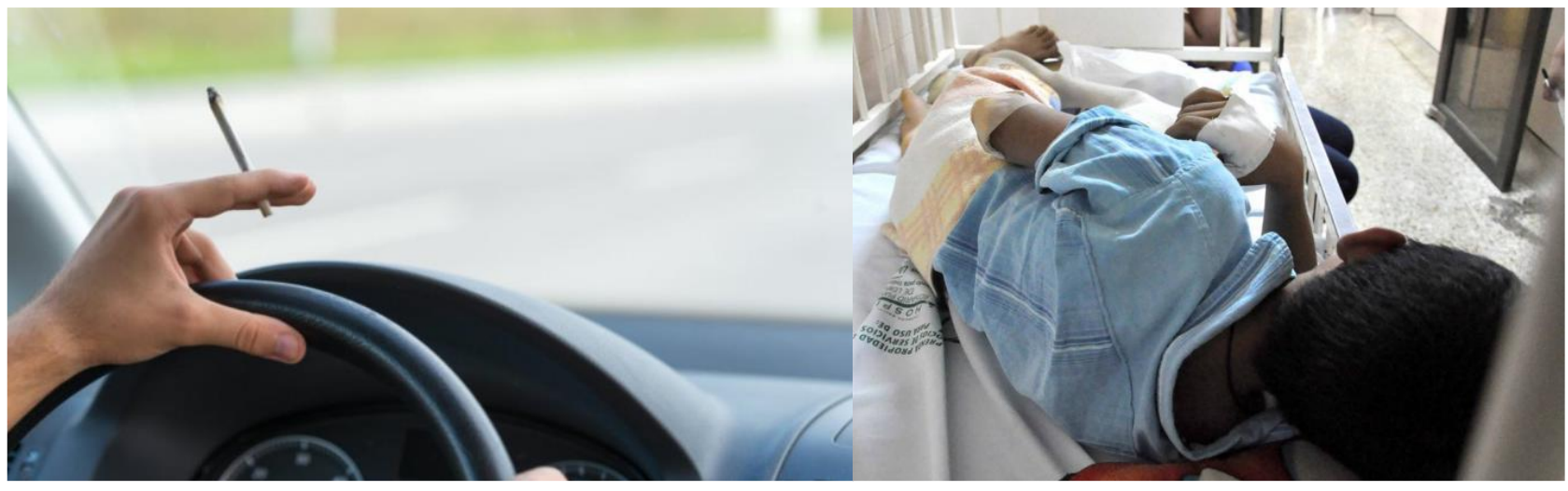

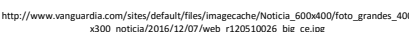

Existe evidencia de aumento de riesgo de accidentes y, donde su uso recreacional está autorizado, son más frecuentes las intoxicaciones accidentales de niños (en los lugares casi se ven tres veces más incidentes de este tipo que donde están proscrita).

\section{Cáncer}

No se encontró evidencia de que fumar marihuana aumente el riesgo de padecer de cáncer (los asociados con fumar tabaco). El consumo de los padres no conlleva a riesgo de cáncer en los hijos.

\section{Riesgo cardiovascular, enfermedad respiratoria e inmunidad}

Consideran que aún no existe evidencia concluyente en sentido cardiovascular, aunque se debe indagar más si se relaciona con ataques al corazón. Fumar de manera regular se relaciona con irritación bronquial (tos y flemas) pero, al dejar de fumar, desaparecen tales manifestaciones. El comité no pudo concluir si fumar marihuana se relaciona con EPOC o asma.

No existe aún evidencia de efectos de los cannabinoides en el sistema inmunológico. Existe algún grado de evidencia (aún limitada) de efectos antiinflamatorios. 


\section{Salud mental}

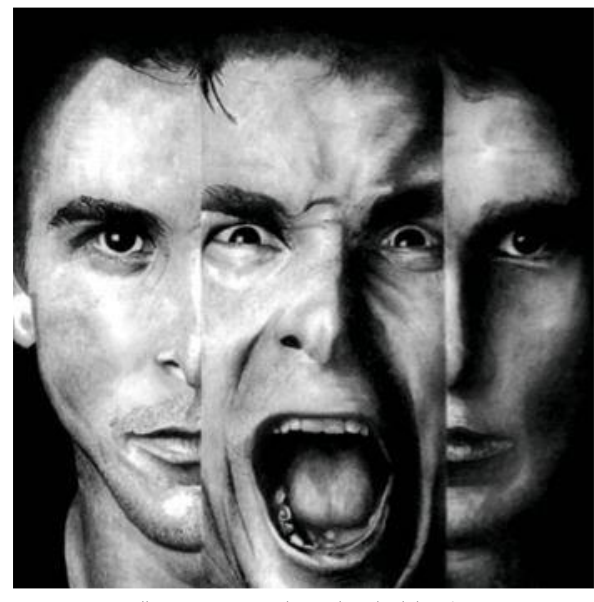

La evidencia relaciona el uso de la marihuana con enfermedades mentales tales como la esquizofrenia, la ansiedad social y la depresión.

\section{¿Paradojas?}

Asimismo, se ha visto que en personas con esquizofrenia y otras psicosis, el consumo de la marihuana puede asociarse a un mejor aprendizaje y de memoria.
Lo grandes consumidores que tienen enfermedad bipolar son más propensos a tener pensamientos suicidas y a un aumento de los síntomas que los que no consumen.

\section{La frecuencia y los problemas}

El uso más frecuente de cannabis conlleva a un uso más problemático entendido como aquel consumo que está generando problemas al propio consumidor o a su entorno y dentro de estos problemas incluiríamos los problemas de salud física, psíquica, problemas sociales e incluso conductas de riesgo que pueden poner en peligro la vida o la salud del consumidor. Por eso, el uso a edades más tempranas se acompaña de mayor frecuencia de uso problemático.

\section{Se sabe y se confirma que...}

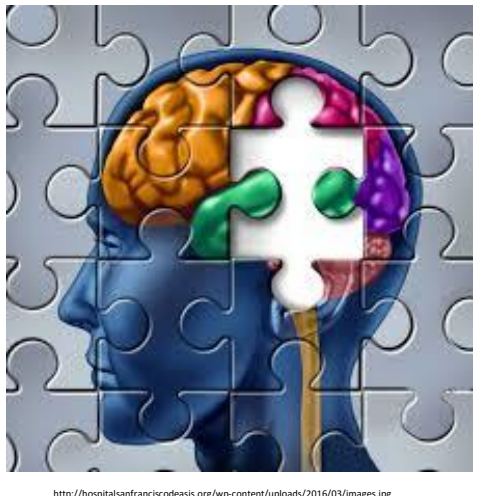

Luego del consumo el aprendizaje, la memoria y la atención se alteran. No se tiene evidencia de si luego del consumo frecuente persisten las alteraciones en estos aspectos (secuelas). Claramente se relaciona su consumo con fracaso escolar. Encontraron pruebas limitadas del consumo con tasas de desempleo y bajos ingresos. 


\section{¿Otras sustancias?}

Existen pruebas (aún limitadas) de su relación con el aumento de consumo de cigarrillos. Existe evidencia moderada de la relación entre consumo de cannabis y el de otras sustancias psicoactivas

\section{En torno a las embarazadas}

Se relaciona con bajo peso al nacer, pero reconocen que aún no existe evidencia clara de asociaciones entre cannabis y embarazo.

\section{Una gran conclusión}

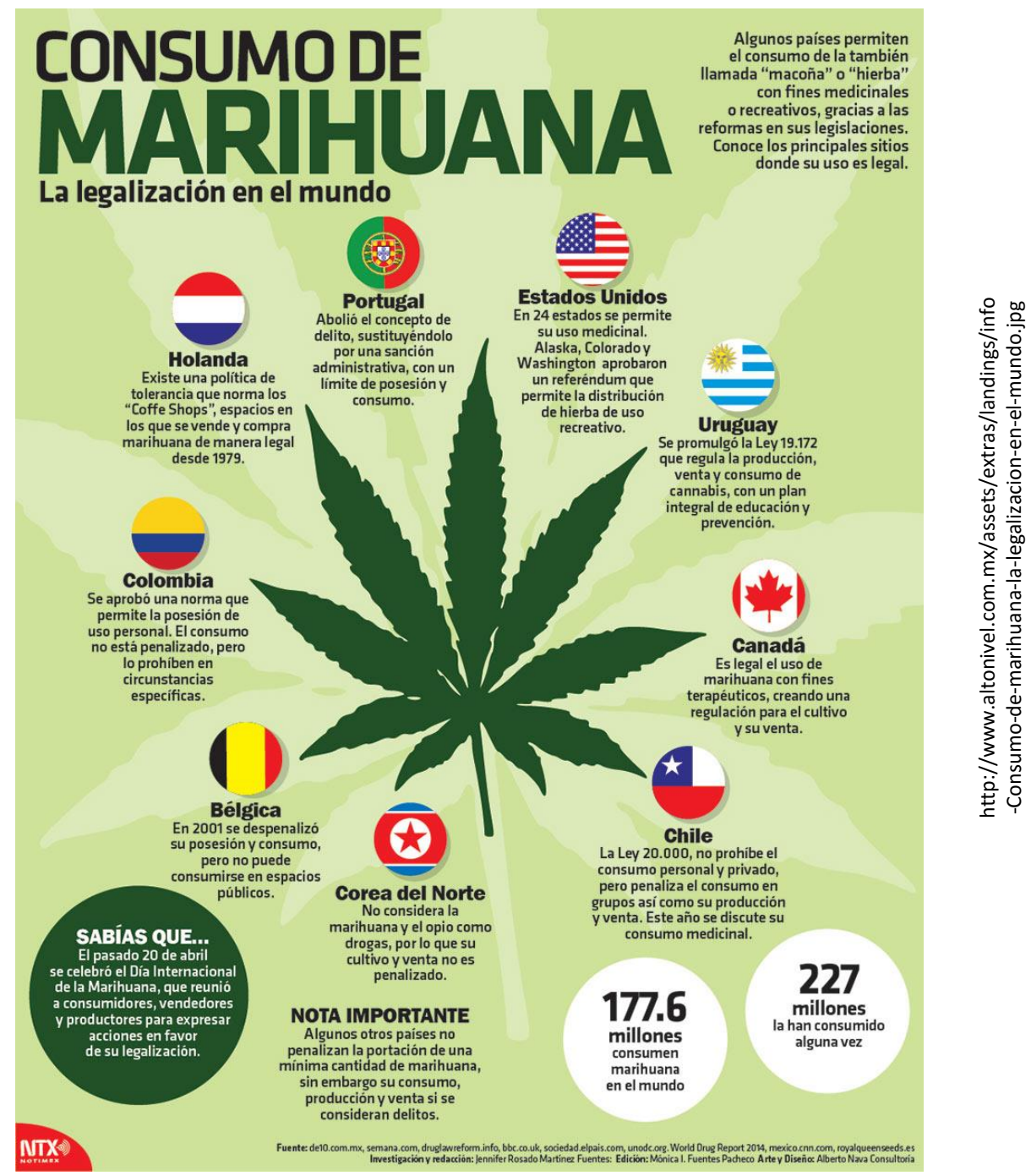

El comité hizo énfasis en la necesidad de hacer muchos más estudios y hacen notar que en tanto esté proscrita, por ejemplo, por parte de la DEA como sustancia tipo 1 (sustancias controladas como una droga sin uso medicinal) las necesarias investigaciones se verán limitadas.

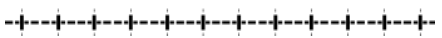

